Research Article

\title{
Micromechanical Properties of Steel-Fiber-Reinforced Cementitious Composites Characterized with Nanoindentation
}

\author{
Yan-Ru Zhao $\mathbb{D}^{1,2}$ Lei Wang, ${ }^{2,3}$ and Yan-Ying Dong ${ }^{1}$ \\ ${ }^{1}$ School of Civil Engineering, Inner Mongolia University of Technology, Hohhot 010051, China \\ ${ }^{2}$ Inner Mongolia Key Laboratory of Civil Engineering Structure and Mechanics, Hohhot 010051, China \\ ${ }^{3}$ College of Science, Inner Mongolia University of Technology, Hohhot 010051, China
}

Correspondence should be addressed to Yan-Ru Zhao; zhaoyanru710523@126.com

Received 3 November 2020; Accepted 7 January 2021; Published 19 January 2021

Academic Editor: Claudio Mazzotti

Copyright (C) 2021 Yan-Ru Zhao et al. This is an open access article distributed under the Creative Commons Attribution License, which permits unrestricted use, distribution, and reproduction in any medium, provided the original work is properly cited.

\begin{abstract}
The micromechanical properties of the steel-fiber-reinforced cementitious composites with different water-binder ratios and silica fume contents were studied by nanoindentation. The elastic modulus, indentation hardness, total input energy, and ratio of the elastic deformation energy to the total input energy were analyzed in the interfacial transition zone (ITZ) and the cement matrix. The results show that with the reduction of water-binder ratio in the range of $0.18-0.24$, the elastic modulus, indentation hardness, elastic deformation capacity, and energy dissipation capacity increased in the ITZ and cement matrix, and the increase of the ITZ was greater than that of the matrix, yet the ITZ did not disappear. With the increase of silica fume content in the range of $0-30 \%$, the weak ITZ was gradually strengthened or even disappeared. In terms of obtaining the stronger ITZ, adding silica fume is more effective than reducing the water-binder ratio. When the water-binder ratio was high at 0.24 , large silica fume contents ( $30 \%)$ had significant effects on enhancing the micromechanical properties of the ITZ and matrix. At a low water-binder ratio of 0.18 , large silica fume contents $(30 \%)$ enhanced the micromechanical properties of the ITZ while degrading those of the cement matrix.
\end{abstract}

\section{Introduction}

With the development of industry and infrastructure construction, steel-fiber-reinforced cementitious composites, with excellent mechanical properties and durabilities, are gradually becoming one of the most widely used materials in civil engineering [1]. In these composites, due to the "wall" effect from the packing of cement particles against the relatively smooth steel-fiber surface, fewer cement particles are present and more water accumulates in the areas surrounding the steel fiber, resulting in relatively loose structures in these areas after hydration of the cement. This area is called the interfacial transition zone (ITZ) [1], and its width is affected by many factors, such as mix proportion, curing age, and regime, and is typically several tens of microns [1]. The ITZ is an important part of steel-fiber-reinforced cementitious composites, but its effects on the mechanical properties, transmission properties, and durabilities of the cementitious composites have not been clearly established. Studies have shown that the ITZ is the weakest link between the cement matrix and reinforcement (aggregate or fiber). Thus, the ITZ plays an important role in determining the properties of the cementitious composites [2-5]. It has been reported that the properties of the ITZ may have a moderate negative influence on the mechanical properties of concrete but not a drastic one [6,7]. The lack of conclusive evidence on the properties of the ITZ is mainly due to the complexity of the cementitious composites and lack of appropriate testing techniques at the microscale.

During the last ten years, nanoindentation has been applied to study the mechanical properties and failure mechanisms of cementitious composites on the micro- and nanoscales. Using nanoindentation, Mondal et al. [8] studied the micromechanical properties of the interface area between cement matrix and sand in mortar with a waterbinder ratio of 0.5 . They reported that the elastic modulus decreased near the edge of the sand grains and increased with the increase of the distance between the testing points and sand surface. Furthermore, the mechanical properties of the ITZ were about $85 \%$ of those of the cement matrix, 
determined by statistical analysis. A study of the elastic modulus of the steel-fiber-cement matrix interfacial zones in high-performance concrete (HPC) was performed by Sorelli et al. [9] using nanoindentation, which showed that the elastic moduli of ITZs with widths of $30-40 \mu \mathrm{m}$ were higher than those of the cement matrix. Wang et al. [10] studied the mechanical properties of the ITZ in steel-fiber-reinforced mortar with different water-binder ratios and silica fume contents using nanoindentation and scanning electron microscopy (SEM). The mechanical properties of the steel-fibermatrix interfacial zones were higher than those of the cement matrix in specimens with water-binder ratios of 0.3 and no silica fume but were relatively poor in specimens with waterbinder ratios of 0.5 . The results also showed that when the ratio of water to binder was 0.3 , the properties of the ITZs decreased with the addition of silica fume. Xu et al. [11] performed nanoindentation testing to study the nanomechanical properties of the ITZs in steel-fiber-reinforced cementitious composites with water-binder ratios of $0.35,0.40$, and 0.45 . They reported that the widths of the ITZs in all the samples were about $40 \mu \mathrm{m}$, and the test points with the lowest elastic moduli and indentation hardnesses were about $20 \mu \mathrm{m}$ away from the steel-fiber surface in the ITZs. When the positions of the test points were fixed, higher water-binder ratios yielded smaller values of the elastic modulus and indentation hardness.

In recent years, in HPC, such as reactive powder concrete (RPC), a low water-binder ratio $(<0.30)$ is often used to obtain high strength, silica fume is often added as a mineral admixture to improve the densification and optimize the microstructure, and steel fiber is added to improve the toughness and ductility of the HPC. Previous studies mainly focused on the micromechanical properties of the HPC under the influence of the above factors, but the micromechanical properties, especially the mechanical properties of the ITZ, have been studied less. In the present study, samples with low water-binder ratios $(0.18$, 0.21 , and 0.24 ) and different silica fume contents were prepared. The effects of the water-cement ratios and silica fume contents on the micromechanical properties of the steel-fiber-matrix interfacial zones in the samples were studied using nanoindentation testing. These results can provide guidance for designing HPC and establishing a multiscale constitutive model.

\section{Experimental Program}

2.1. Raw Materials. Ordinary Portland cement (P.O 42.5) was used, and its chemical composition (\% by mass) is shown in Table 1 . The properties of silica fume are shown in Table 2. Quartz sand, with particle sizes of $150-600 \mu \mathrm{m}$ and an $\mathrm{SiO}_{2}$ content of $99.8 \%$, was used as the fine aggregate. Straight steel fibers with lengths of $1 \mathrm{~cm}$, diameters of $1 \mathrm{~mm}$, and tensile strengths of $2600 \mathrm{MPa}$ were used.

2.2. Mixture Proportions. Water-binder ratios of $0.18,0.21$, and 0.24 and a sand-binder ratio of 0.84 were used in this study. Silica fume contents of $0 \%, 10 \%, 20 \%$, and $30 \%$ (by mass) were used as a cement replacement to maintain a constant total mass of the binder. The content of JSM-1 polycarboxylate superplasticizer was $2 \%$ of the total mass of the binder. The samples were identified with a combination of letters and numbers: WB18, WB21, and WB24 indicating three water-binder ratios, respectively, and SF00, SF10, SF20, and SF30 indicating four silica fume contents, respectively. For example, WB18SF10 indicates that the water-binder ratio of the sample was 0.18 and the silica fume content was $10 \%$.

2.3. Sample Preparation for Nanoindentation Testing. Cubic samples with $20 \mathrm{~mm}$ side lengths were prepared for the nanoindentation testing. The mixing procedure of the cement paste was as follows: the Portland cement, silica fume, and quartz sand were initially mixed for $1 \mathrm{~min}$. Next, water and superplasticizer were added and remixed for 3-5 min to achieve the desired workability and homogeneity. The mixture was poured into a mold and vibrated for 2 minutes using a vibrating table. Finally, lay the steel fiber horizontally on the surface of the mixture and press slightly into the mixture and continue to vibrate it for 1 minute. The sample was demolded and numbered after $24 \mathrm{~h}$ and cured for $28 \mathrm{~d}$ in the standard curing room.

In the nanoindentation tests, extremely smooth sample surfaces are critical for the reliable determination of the mechanical properties of the ITZs $[12,13]$. First, the surfaces of the cured samples were ground with diamond wheels with grit sizes of 400\#, 600\#, 800\#, 1200\#, 1500\#, 2000\#, 2500\#, and $3000 \#$ sequentially until the fiber cross-sections were exposed. Subsequently, the surfaces were polished with polishing pastes containing 2.5 and $0.5 \mu \mathrm{m}$ abrasives to obtain smooth and clean observation surfaces. Finally, the polished samples were cleaned by ultrasonication for $15 \mathrm{~min}$ to remove impurity particles adsorbed on the surfaces.

2.4. Nanoindentation Test. The G200 nanoindenter made by Hysitron Inc. was used in the test. According to the China standard GB/T22458-2008 [14], the test procedure was as follows: the indenter was pressed into the sample at a constant displacement rate of $0.1 \mathrm{~m} / \mathrm{s}$ until the depth reached $1000 \mathrm{~nm}$, after which the load was held for $5 \mathrm{~s}$ before unloading at the same constant rate. A load-depth curve was obtained by continuously recording the indentation load and depth values in this process, as shown in Figure 1, where $h_{\text {max }}$ is the maximum indentation depth, $h_{\mathrm{f}}$ is the final depth of contact impression after unloading, and $P_{\max }$ is the peak indentation load.

According to the principle of Oliver-Pharr [15], the indentation hardness $H$ and modulus $M$ of each test point can be determined using the information obtained during unloading region of the load-depth curve (as shown in Figure 1) as follows:

$$
\begin{gathered}
H=\frac{P_{\max }}{A_{\mathrm{c}}}, \\
M=\frac{\sqrt{\pi} S}{2 \beta \sqrt{A_{c}}},
\end{gathered}
$$

where $A_{\mathrm{c}}$ is the contact area at the maximum load, $S$ is the slope at the beginning of the unloading curve, and $\beta$ is the 
TABle 1: Chemical composition of ordinary Portland cement.

\begin{tabular}{lccccc}
\hline $\mathrm{CaO}(\%)$ & $\mathrm{SiO}_{2}(\%)$ & $\mathrm{Al}_{2} \mathrm{O}_{3}(\%)$ & $\mathrm{SO}_{3}(\%)$ & $\mathrm{MgO}(\%)$ & $\mathrm{Fe}_{2} \mathrm{O}_{3}(\%)$ \\
\hline 62.9 & 20.7 & 4.84 & 3.56 & 2.15 & 3.18 \\
\hline
\end{tabular}

Table 2: Properties of silica fume.

\begin{tabular}{lccccc}
\hline $\mathrm{SiO}_{2} /(\%)$ & $\mathrm{Al}_{2} \mathrm{O}_{3} /(\%)$ & $\mathrm{Fe}_{2} \mathrm{O}_{3} /(\%)$ & $\mathrm{CaO}+\mathrm{MgO} /(\%)$ & $\mathrm{K}_{2} \mathrm{O}+\mathrm{Na}_{2} \mathrm{O} /(\%)$ & Specific surface/(m $\left.{ }^{2} \cdot \mathrm{g}^{-1}\right)$ \\
\hline$\geq 97$ & 1.2 & 1.2 & 1.4 & 0.2 & $15-20$ \\
\hline
\end{tabular}

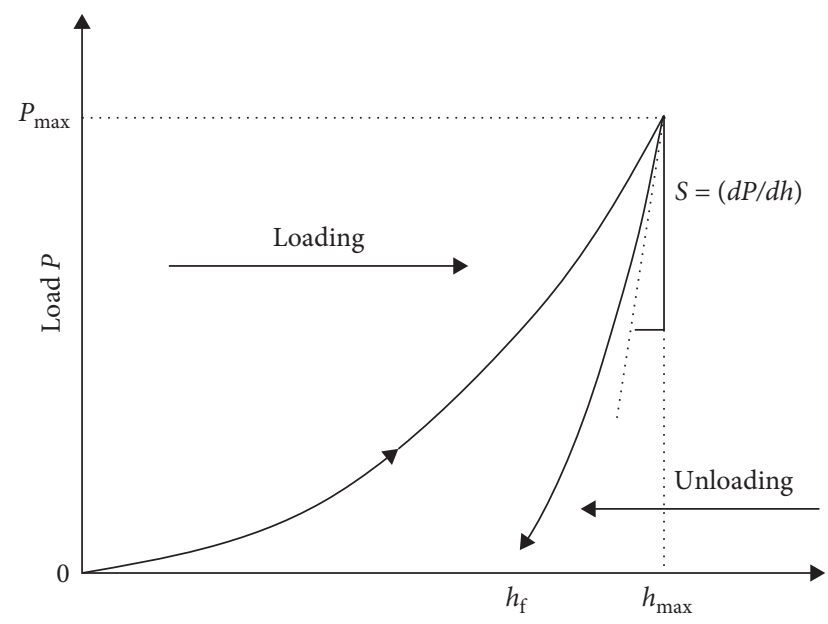

Figure 1: A typical load-depth curve.

correction coefficient of the indenter, where $\beta=1.012$ for the pyramid Berkovich indenter used in the present test [14].

Assuming that the cement matrix is isotropic, the elastic modulus $E$ of a sample can be calculated as follows:

$$
E=\left(1-v^{2}\right)\left[\frac{1}{M}-\frac{\left(1-v_{i}^{2}\right)}{E_{i}}\right]^{-1}
$$

where $v$ is the Poisson ratio of the sample, which is generally 0.25 for the cement material, and $E_{i}$ and $v_{i}$ are the elastic modulus and the Poisson ratio of the indenter, respectively. For the diamond Berkovich indenter used in the present test, the elastic modulus was $E_{i}=1140 \mathrm{GPa}$ and the Poisson ratio was $v_{i}=0.07$ [16].

To obtain sufficient data for analysis, 50 test points arranged in 5 rows and 10 columns on the surface of each sample were selected for the nanoindentation tests. The horizontal and vertical distances between two adjacent test points were $10 \mu \mathrm{m}$. The distribution of these test points is shown in Figure 2.

\section{Nanoindentation Test Result Analysis}

3.1. Load-Depth Curves. The load-depth curves of 10 test points on the steel-fiber section are shown in Figure 3(a). These smooth curves almost coincided, and their peak loads were all approximately $105 \mathrm{mN}$. The deviations between the test points on the steel-fiber section were very small, which indicates that nanoindenter measurements were reliable. For samples with different water-binder ratios and without silica fume, typical load-depth curves of the test points on the cement matrix $60 \mu \mathrm{m}$ away from the steel-fiber surface are shown in Figure 3(b). The peak indentation load decreased significantly from $67 \mathrm{mN}$ to nearly $32 \mathrm{mN}$ with the increase of water-cement ratio. This indicates that the microstructure and mechanical properties of the cement matrix were significantly different due to the different water-cement ratios.

It should also be noted that some of the measured loaddepth curves exhibited displacement jumps in the loading phase, as shown in Figure 3(c), which could be due to the presence of large voids or cracking of the cement matrix. These irregular curves should be discarded in the calculation of the indentation hardness $H$ and elastic modulus $E$ [17].

3.2. Elastic Modulus $E$ and Indentation Hardness $H$. The elastic modulus is one of the important mechanical properties of concrete for measuring the concrete's resistance to being deformed elastically, and it is an important parameter for calculating structural deformation and for stress and crack control. Indentation hardness measures the resistance of solid materials to permanent shape changes due to a compressive load from a sharp object [17]. The elastic moduli and indentation hardnesses at all 50 test points are shown in Figures 4(a) and 4(b). The mean values of the elastic modulus and hardness for 5 points with the same distances from the steel-fiber surface were fitted with interpolation function using a B-spline curve in Origin9.0, as shown in Figure 4. The elastic modulus and indentation hardness decreased dramatically at first, after which they increased and gradually stabilized with the increase of the distance from the steel-fiber surface. The obvious valley in the curve corresponds to the ITZ, which is the weakest part of cementitious composites, as shown between the two dashed lines in Figure 4.

3.3. The Total Input Energy and Ratio of the Released Elastic Energy to the Total Input Energy. The total input energy can be determined by calculating the area under the loading section in the load-depth curve, expressed as follows:

$$
W_{\mathrm{t}}=\int_{0}^{h_{\max }} P \mathrm{~d} h .
$$

The elastic deformation energy can be determined by the area under the unloading curve, expressed as follows: 

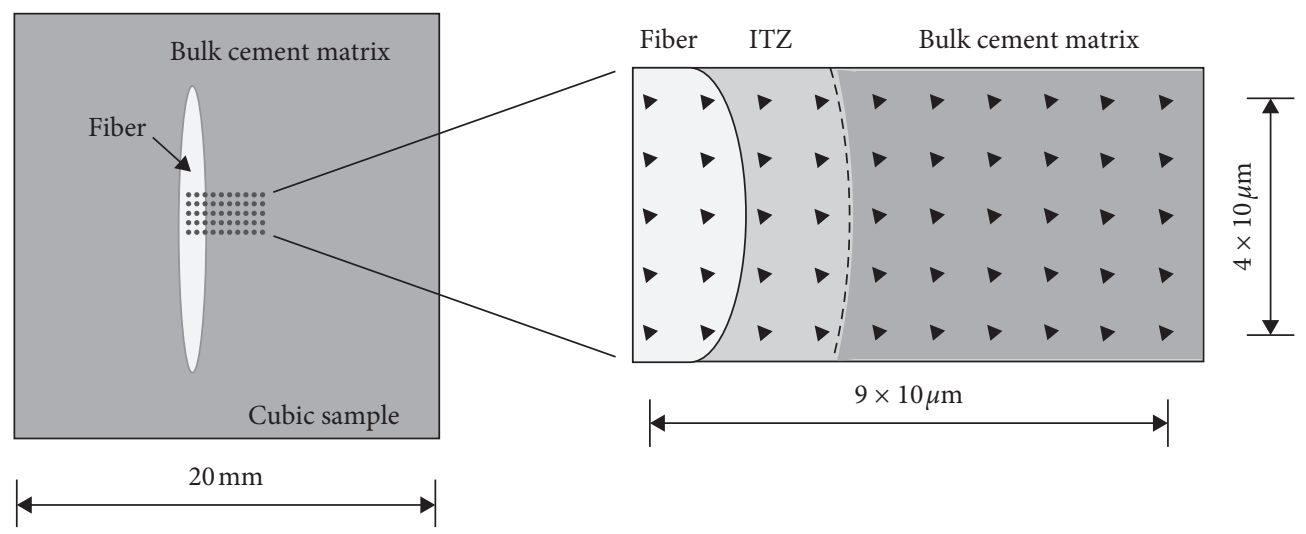

FIgURE 2: Test point distribution for nanoindentation tests.

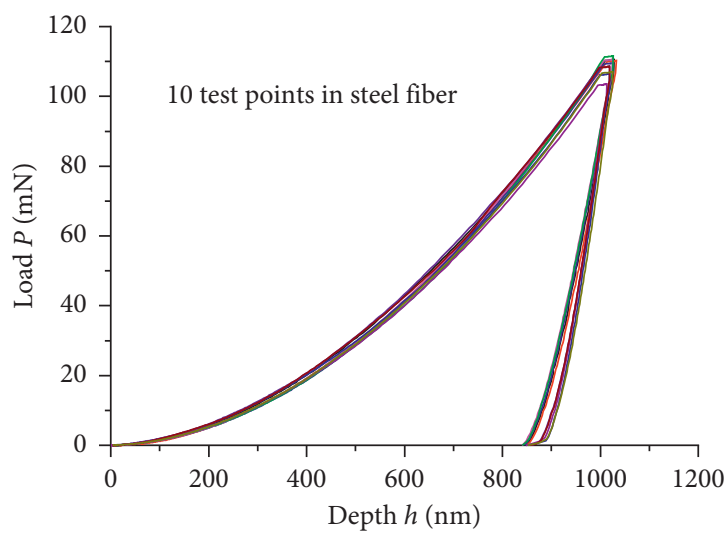

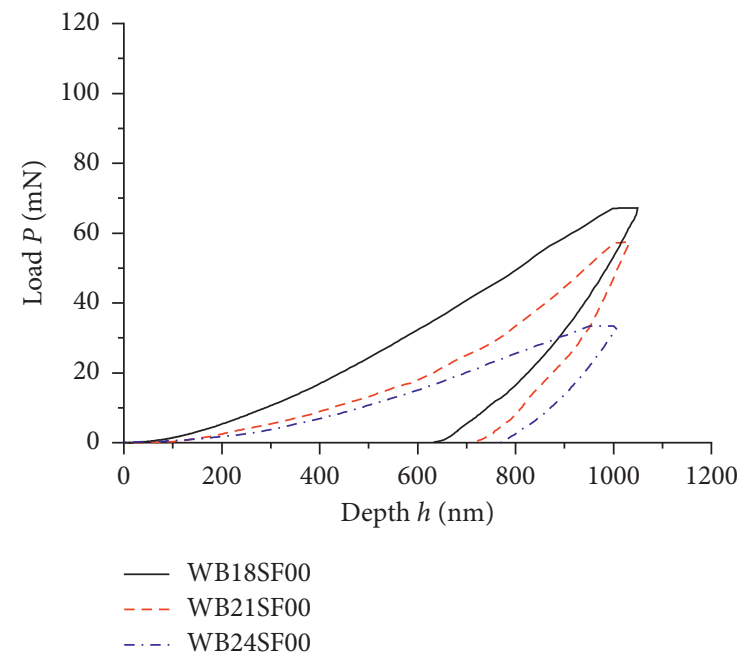

(b)

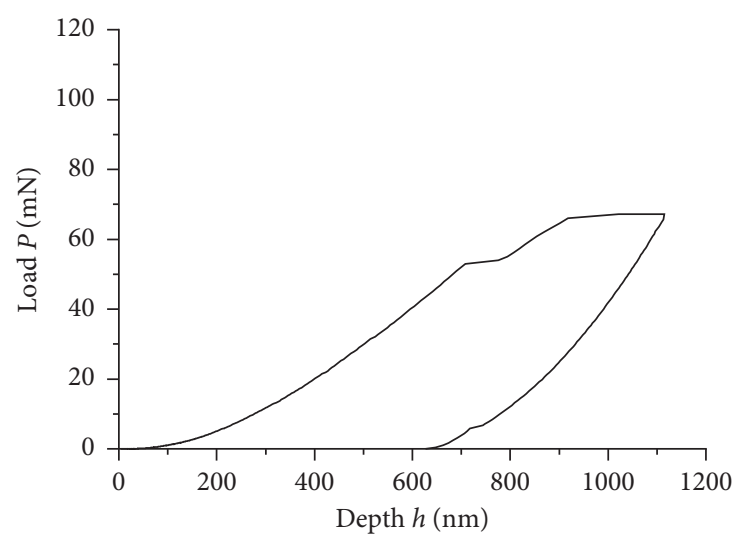

(c)

Figure 3: Load-depth curves of test points. (a) Load-depth curves of the test points in steel fiber. (b) Load-depth curves of test points in matrix $60 \mu \mathrm{m}$ away from the steel-fiber surface. (c) Irregular load-depth curve. 


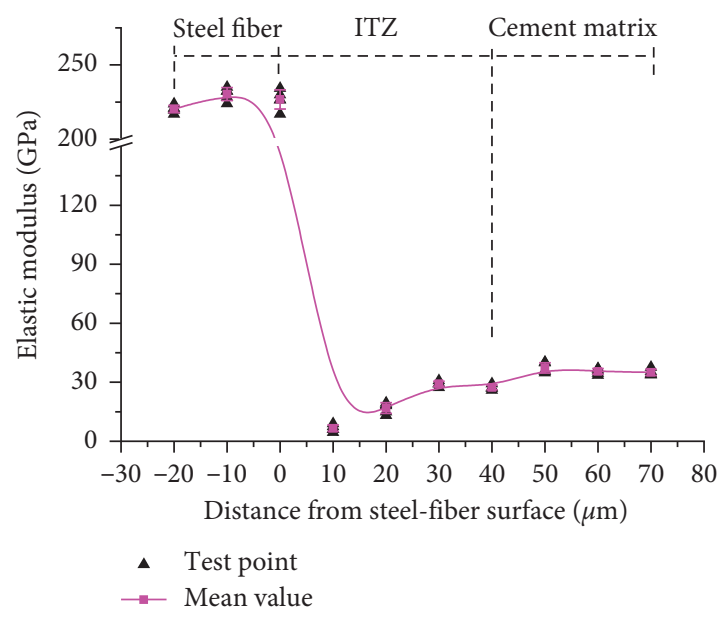

(a)

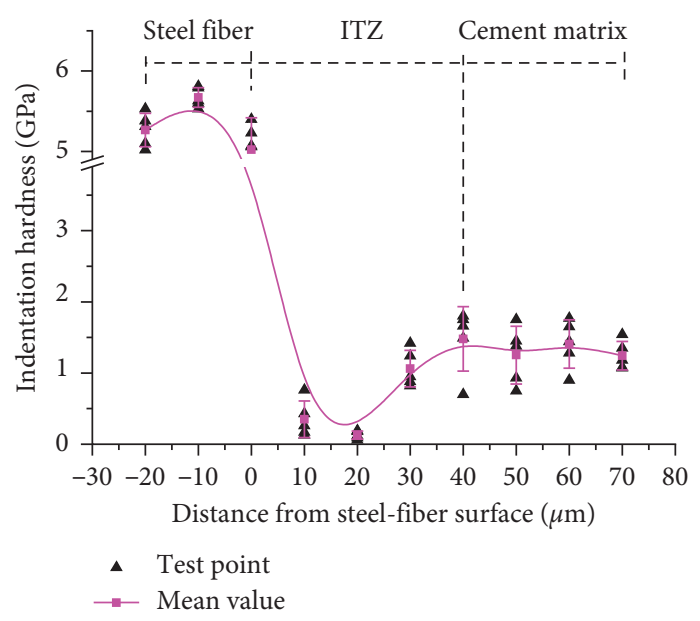

(b)

FIGURE 4: Test indices versus distance from the steel-fiber surface. (a) Elastic modulus. (b) Indentation hardness.

$$
W_{\mathrm{e}}=\int_{h_{f}}^{h_{\max }} P \mathrm{~d} h
$$

The dissipated energy can be calculated as follows:

$$
W_{\mathrm{p}}=W_{\mathrm{t}}-W_{\mathrm{e}}
$$

The ratio of the elastic deformation energy to the total input energy, $\eta$, was defined as follows:

$$
\eta=\frac{W_{\mathrm{e}}}{W_{\mathrm{t}}}
$$

For sample WB18SF00, the $W_{\mathrm{t}}, W_{\mathrm{e}}, W_{\mathrm{p}}$, and $\eta$ values of each test point were calculated according to Equations (3)-(6). The values for test points located in the steel fiber, ITZ, and matrix were averaged and are listed in Table 3.

The total input energy $W_{\mathrm{t}}$ is the sum of the elastic deformation and dissipation energies when a compressive force is applied. The index $\eta$ can be used to determine whether elastic deformation or permanent deformation is dominant during the loading process. A smaller value of $\eta$ indicates that the stored elastic deformation energy is lower and the dissipation energy is higher $[18,19]$. It can be seen from Table 3 that the elastic deformation and dissipation energies of the test points in different regions from high to low were as follows: steel fiber $>$ cement matrix > ITZ, which indicates that the elastic deformation and energy dissipation capacities of steel fiber were the highest, and those of the cement matrix were higher than those of the ITZ. The ratio $\eta$ of the elastic deformation energy to the total input energy was only $20-30 \%$ for all test points, indicating that permanent deformation was dominant during the loading process. Moreover, the ratio of the dissipation energy to the total input energy was the highest for the test points in steel fiber, and that in the ITZ was higher than that in the cement matrix.

\section{Discussion}

4.1. Effect of Water-Binder Ratio on Elastic Modulus and Indentation Hardness. The water-binder ratio has a significant influence on the cement hydration degree and density of the cement microstructure, and thus, it is an important factor that affects the elastic modulus and indentation hardness. Figures 5(a) and 5(b) show the elastic modulus and indentation hardness values of the test points for the samples with different water-binder ratios and silica fume contents of $0 \%$. There were significant differences in the elastic moduli and indentation hardnesses of the steel fiber, ITZ, and cement matrix. With the decrease of the waterbinder ratio, the increase of elastic modulus of the cement matrix and ITZ indicates the improvement of the elastic deformation capacity, and the increase of the indentation hardnesses indicates the improvement of the resistance to permanent deformation. The ITZ is the region between two dashed lines in Figure 5. The ITZ width decreased with the decrease of the water-binder ratio, indicating that the ITZ was strengthened but not eliminated.

The elastic moduli and indentation hardnesses of the ITZ and cement matrix under different water-binder ratios are listed in Table 4. The results indicate that the micromechanical property indexes of the ITZ and cement matrix increased significantly by decreasing the water-binder ratio, and the increase of the ITZ was greater than that of cement matrix.

4.2. Effect of Silica Fume Content on Elastic Modulus and Indentation Hardness. Figures 6 and 7 show the elastic modulus and indentation hardness values at different distances from the steel-fiber surface under different silica fume contents and water-cement ratio. When the silica fume content was $10 \%$, the variation ranges of the elastic moduli and indentation 
TABLE 3: Results of the energy indices of sample WB18SF00.

\begin{tabular}{|c|c|c|c|c|c|}
\hline Test points position & $W_{\mathrm{t}}\left(10^{-9} \mathrm{~J}\right)$ & $W_{\mathrm{e}}\left(10^{-9} \mathrm{~J}\right)$ & $W_{\mathrm{p}}\left(10^{-9} \mathrm{~J}\right)$ & $\eta=W_{\mathrm{e}} / W_{\mathrm{t}}(\%)$ & $W_{\mathrm{p}} / W_{\mathrm{t}}=1-\eta(\%)$ \\
\hline Steel fiber & 40.66 & 8.30 & 32.36 & 20.41 & 79.59 \\
\hline ITZ & 9.79 & 2.09 & 7.69 & 23.51 & 76.49 \\
\hline Cement matrix & 18.86 & 5.41 & 13.45 & 29.11 & 70.88 \\
\hline
\end{tabular}

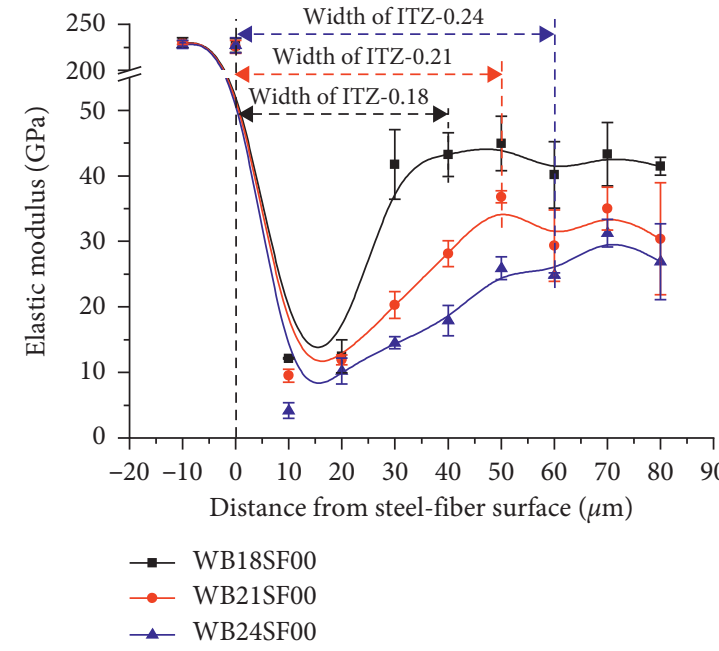

(a)

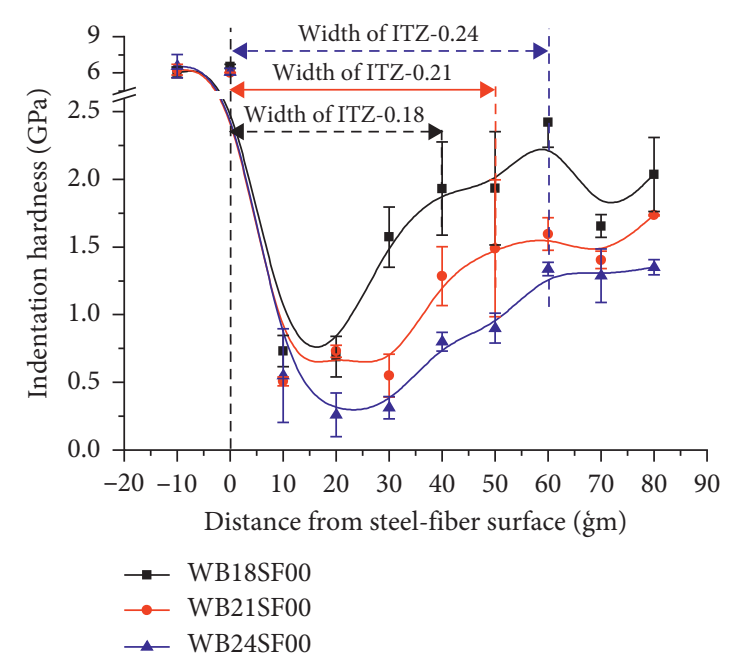

(b)

FIGURE 5: Test indices versus distance from the steel-fiber surface under different water-cement ratios. (a) Elastic modulus. (b) Indentation hardness.

TABLE 4: Test indices of ITZ and cement matrix under different water-binder ratios.

\begin{tabular}{lcccc}
\hline \multirow{2}{*}{ Sample } & & ITZ & \multicolumn{2}{c}{ Cement matrix } \\
& Elastic modulus & Indentation hardness & Elastic modulus & Indentation hardness \\
\hline WB24SF00 & 7.8 & 0.3 & 27.5 & 1.32 \\
WB18SF00 & 13.5 & 0.79 & 42.5 & 2.03 \\
Increased range & $73.1 \%$ & $163 \%$ & $54.5 \%$ & $53.4 \%$ \\
\hline
\end{tabular}

hardnesses of the samples with three water-cement ratios were very large, and the valleys in the curves, corresponding to the ITZ, were very obvious. When the silica fume content increased from 20 to $30 \%$, the elastic moduli of the interface area and the matrix were nearly the same, as were the hardnesses. Furthermore, the valleys in the curves disappeared. This indicates that with the increase of silica fume content, the micromechanical properties of the ITZ improved, and the weak ITZ was gradually strengthened or even disappeared. The ITZ was strengthened but did not disappear with the decrease of waterbinder ratio (see Section 4.1), indicating that adding silica fume is more effective than reducing the water-binder ratio in terms of obtaining the stronger ITZ.

However, the amount of silica fume cannot be increased indefinitely to improve the ITZ and matrix micromechanical properties. The lines labeled (1) and (2) in Figure 6 represent the elastic modulus of the ITZ and cement matrix, respectively. As shown in Figures 6(a)$6(\mathrm{c})$, the lengths of lines (1) increased, and the lengths of the lines (2) decreased with the increase of silica fume content. This indicates that adding silica fume can enhance the properties of the ITZ but degrade the properties of the cement matrix. Therefore, caution should be taken when adding a large amount of silica fume to eliminate the ITZ.

\subsection{The Combined Effect of Water-Binder Ratio and Silica} Fume Content on Elastic Modulus and Indentation Hardness. As shown in Figures 8(a) and 9(a), when the waterbinder ratio was relatively low at 0.18 , the ITZ and cement matrix properties first increased and subsequently decreased with the increase of silica fume content. Adding excessive silica fume (30\%) reduced the amount of improvement to the ITZ properties, and the cement matrix properties were reduced to minimum values or to values lower than those without silica fume. Therefore, the silica fume content should not be too high at a low water-binder ratio (0.18).

As shown in Figures 8(c) and 9(c), when the water-binder ratio was relatively high at 0.24 , the elastic moduli and indentation hardnesses of the ITZ properties gradually increased 


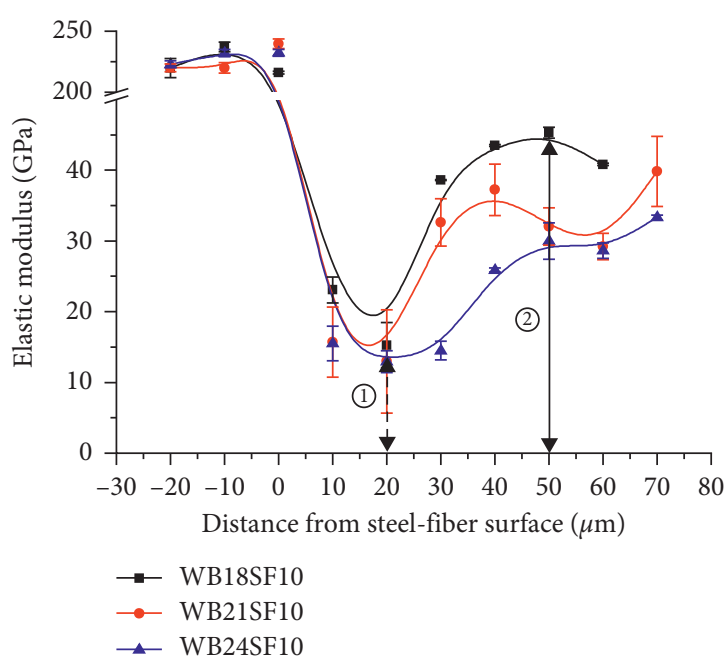

(a)

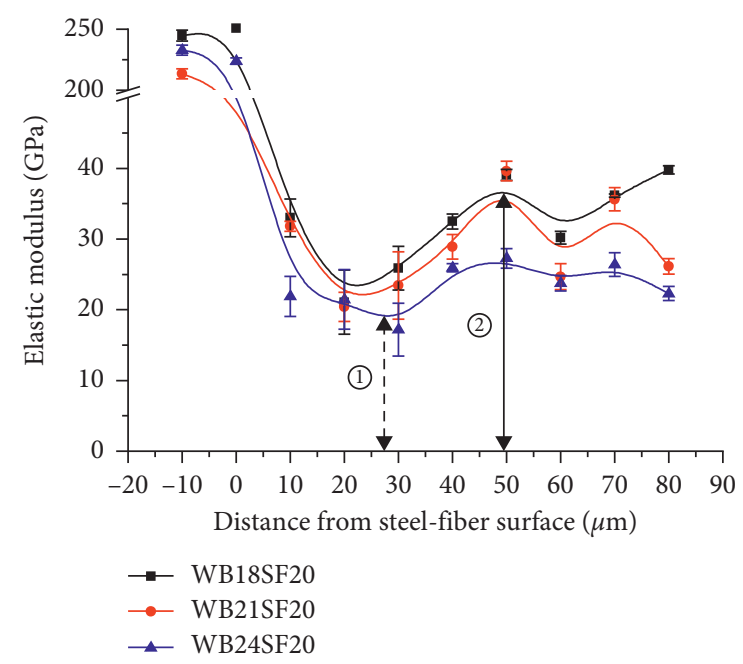

(b)

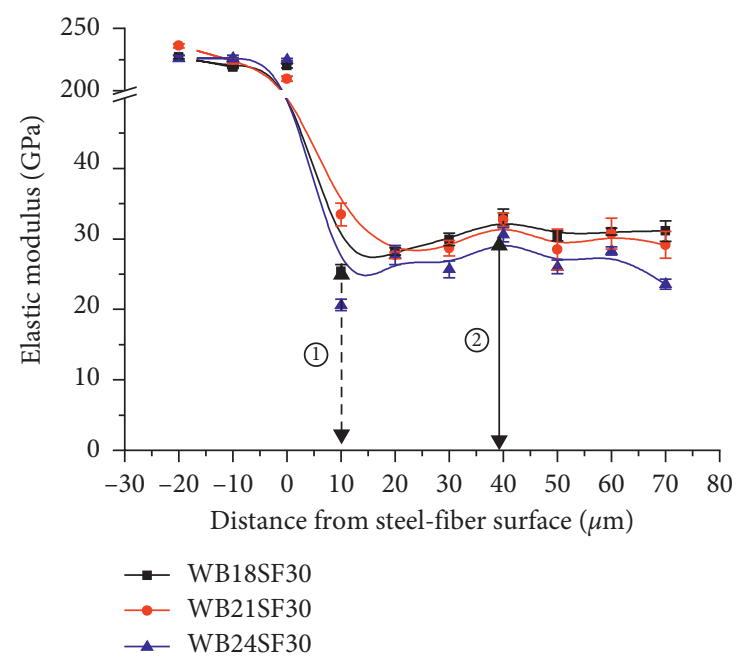

(c)

FIgURE 6: Elastic modulus with distance from the steel-fiber surface for different silica fume contents. (a) Silica fume content of $10 \%$. (b) Silica fume content of $20 \%$. (c) Silica fume content of $30 \%$.

with the increase of silica fume content and reached maximum values when the silica fume content was $30 \%$. The cement matrix properties first increased and subsequently decreased with the increase of silica fume content. When the silica fume content was $30 \%$, the cement matrix properties were not the highest observed in this study, but they were higher than those without silica fume. This indicates that, with a high water-binder ratio (0.24), a large silica fume content has a more significant effect on enhancing the micromechanical properties of the cement matrix. In addition, the improvement of the ITZ properties was greater than that of the cement matrix when a large amount of silica fume was added at a high water-binder ratio $(0.24)$.

In conclusion, the silica fume content should not be too high but should match the water-binder ratio, and a moderate silica fume content can increase the overall properties of cementitious composites to a maximum extent.

\subsection{The Total Input Energy $W_{t}$ and the Ratio $\eta$ of the Elastic Deformation Energy to the Total Input Energy}

4.4.1. The Effect of Water-Binder Ratio on $W_{t}$ and $\eta$. The $W_{\mathrm{t}}$ and $\eta$ values with different water-binder ratios and a silica fume content of $0 \%$ are shown in Table 5 . With the decrease of the water-binder ratio, the total input energy $W_{\mathrm{t}}$ of the ITZ and cement matrix increased, and the elastic deformation and energy dissipation capacities were improved. With the reduction of the water-binder ratio, the $\eta$ values of the ITZ and cement matrix increased, indicating that the increase of the elastic deformation energy was larger than that of dissipation energy.

Furthermore, at the same water-binder ratios, the total input energy $W_{\mathrm{t}}$ of the ITZ was less than that of the cement matrix, and the elastic deformation and energy dissipation capacities of the ITZ were lower than those of the cement matrix. The $\eta$ value of the ITZ was higher than that of the 


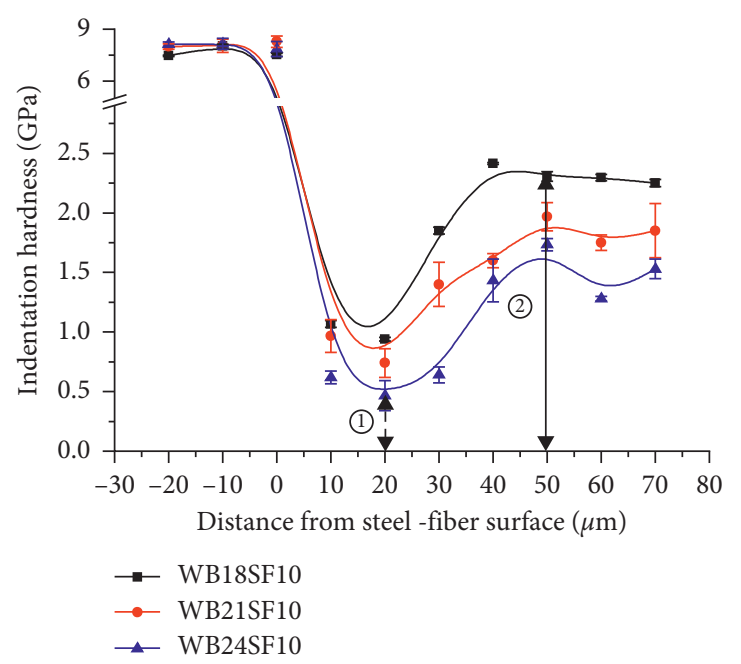

(a)

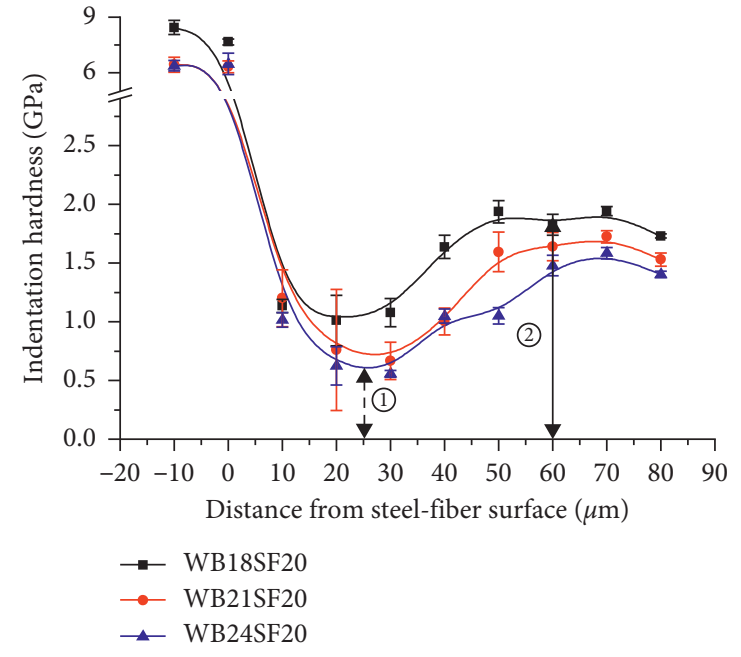

(b)

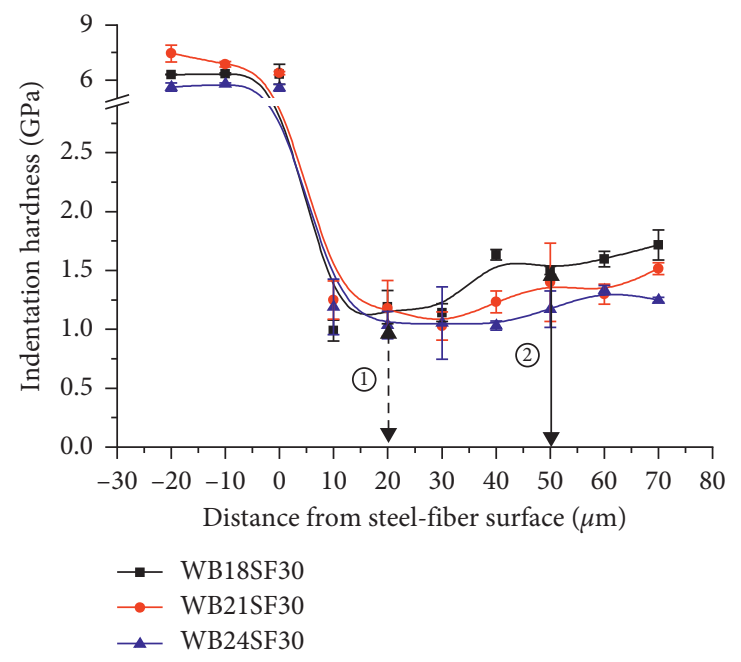

(c)

FiguRe 7: Indentation hardness with distance from the steel-fiber surface for different silica fume contents. (a) Silica fume content of $10 \%$. (b) Silica fume content of $20 \%$. (c) Silica fume content of $30 \%$.

cement matrix, indicating that the proportion of the dissipated energy of the ITZ was higher than that of the cement matrix.

\subsubsection{The Combined Effect of Water-Binder Ratio and Silica} Fume Content on Wt and $\eta$. The $W_{\mathrm{t}}$ and $\eta$ of the test points with different water-binder ratios and silica fume contents are listed in Table 6. Under the combined influence of the two factors (silica fume and water-binder ratio), the changes of micromechanical properties of cementitious composites did not show discernable trends, and the total input energy $W_{\mathrm{t}}$ and the ratio $\eta$ were basically random. However, the following trends can be found in Table 6 :

(1) For the samples with low water-binder ratios (0.18) and large silica fume contents (30\%), the total input energy $W_{\mathrm{t}}$ and the ratio $\eta$ of the elastic deformation energy relative to the total input energy were relatively low for all test points in the cement matrix, indicating that adding excessive silica fume can reduce the mechanical properties of the cement matrix when the water-binder ratio is relatively low (0.18).

(2) When the silica fume content was $30 \%$, the values of $\eta$ of the cement matrix and ITZ were relatively low, indicating that large silica fume contents lead to a decline in the elastic deformation capacities of the cement matrix and ITZ.

4.5. Profile Characteristics of Elastic Modulus and Indentation Hardness. A variety of elastic moduli and indentation hardness profiles have been reported for the ITZ [20-23]. In all these test results, the elastic modulus and indentation hardness were found to be different in the ITZ but relatively constant in the cement matrix. According to hydration degree and bonding strength of the ITZ, the trend of elastic modulus and indentation hardness in the ITZ was classified into four types [24], as shown in Figure 10(a). However, the elastic modulus and 


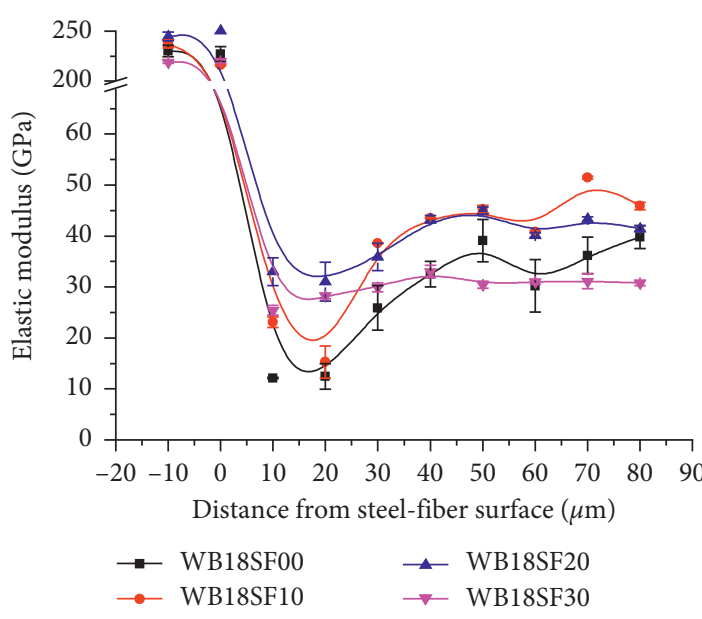

(a)

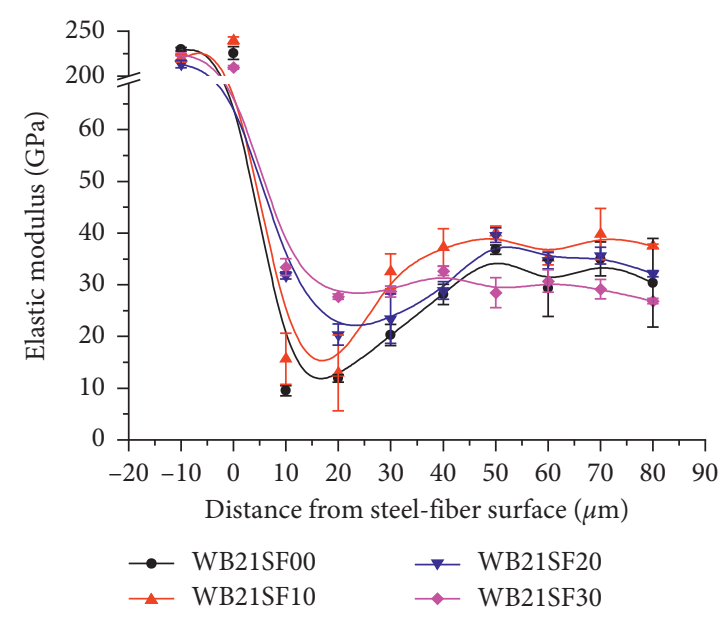

(b)

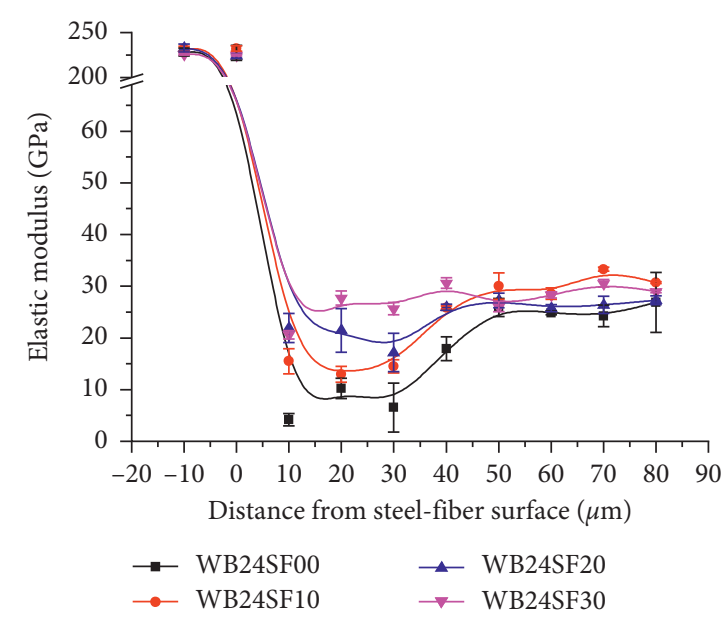

(c)

Figure 8: Elastic modulus with distance from the steel-fiber surface for different silica fume contents and water-binder ratios. (a) Waterbinder ratio of 0.18 . (b) Water-binder ratio of 0.21 . (c) Water-binder ratio of 0.24 .

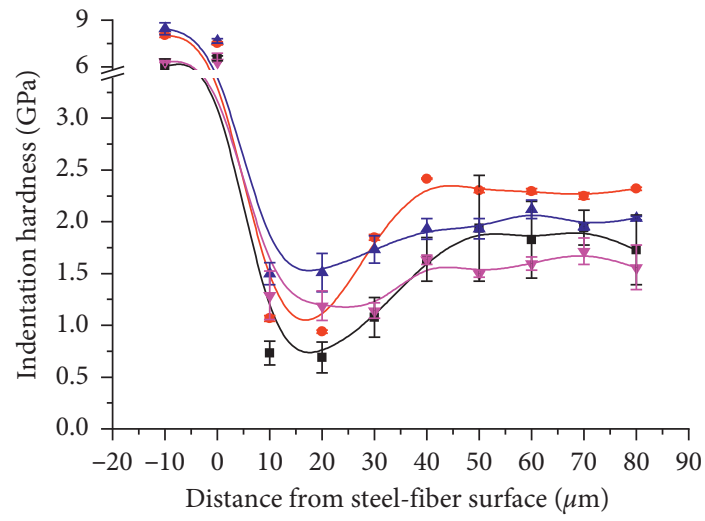

$\rightarrow$ WB18SF00 $\rightarrow$ WB18SF20
$\rightarrow$ WB18SF30

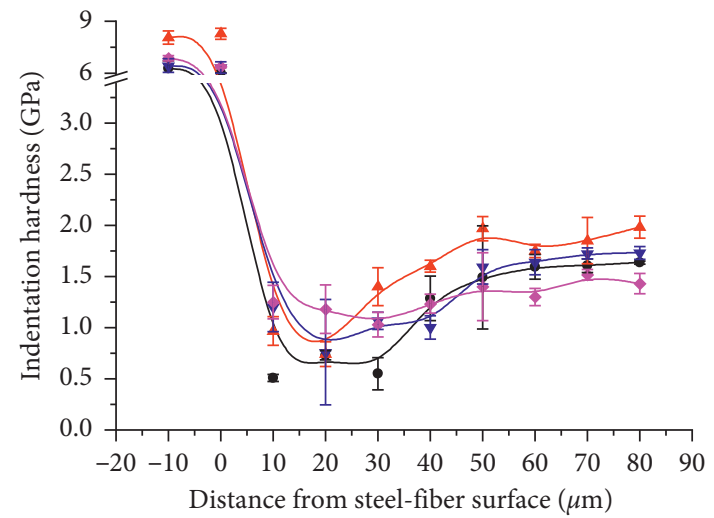

$\rightarrow$ WB21SF00 $\rightarrow$ WB21SF20 (b)

Figure 9: Continued. 


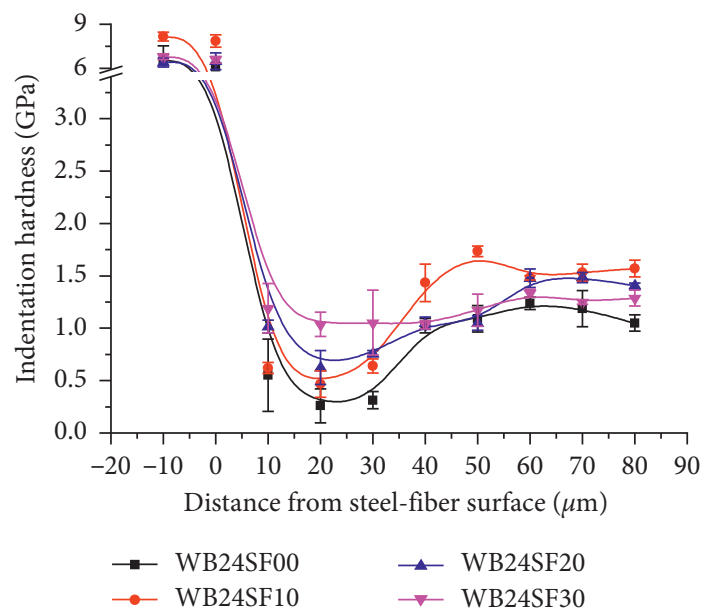

(c)

FIGURE 9: Indentation hardness with distance from the steel-fiber surface at different silica fume contents and water-binder ratios. (a) Water-binder ratio of 0.18 . (b) Water-binder ratio of 0.21 . (c) Water-binder ratio of 0.24 .

TABLE 5: $W_{\mathrm{t}}$ and $\eta$ at different water-binder ratios when silica fume content was $0 \%$.

\begin{tabular}{|c|c|c|c|c|c|c|c|c|}
\hline \multirow{2}{*}{ Sample } & \multicolumn{2}{|c|}{$W_{\mathrm{t}}\left(10^{-9} \mathrm{~J}\right)$} & \multicolumn{2}{|c|}{$W_{\mathrm{e}}\left(10^{-9} \mathrm{~J}\right)$} & \multicolumn{2}{|c|}{$W_{\mathrm{p}}\left(10^{-9} \mathrm{~J}\right)$} & \multicolumn{2}{|c|}{$\eta=W_{\mathrm{e}} / W_{\mathrm{t}}(\%)$} \\
\hline & ITZ & Cement matrix & ITZ & Cement matrix & ITZ & Cement matrix & ITZ & Cement matrix \\
\hline WB24SF00 & 8.08 & 12.41 & 1.70 & 2.98 & 6.38 & 9.43 & 20.99 & 24.02 \\
\hline WB21SF00 & 9.53 & 13.74 & 2.03 & 3.58 & 7.50 & 10.16 & 21.35 & 26.05 \\
\hline WB18SF00 & 9.79 & 18.86 & 2.30 & 5.49 & 7.49 & 13.37 & 23.51 & 29.12 \\
\hline
\end{tabular}

TABLE 6: $W_{\mathrm{t}}$ and $\eta$ for different water-binder ratios and silica fume contents.

\begin{tabular}{|c|c|c|c|c|c|}
\hline \multirow{2}{*}{ Water-binder ratio } & \multirow{2}{*}{ Silica fume content (\%) } & \multicolumn{2}{|c|}{ ITZ } & \multicolumn{2}{|c|}{ Cement matrix } \\
\hline & & $W_{\mathrm{t}}\left(10^{-9} \mathrm{~J}\right)$ & $\eta=W_{\mathrm{e}} / W_{\mathrm{t}}(\%)$ & $W_{\mathrm{t}}\left(10^{-9} \mathrm{~J}\right)$ & $\eta=W_{\mathrm{e}} / W_{\mathrm{t}}(\%)$ \\
\hline \multirow{4}{*}{0.18} & 0 & 9.79 & 23.51 & 18.86 & 29.12 \\
\hline & 10 & 7.25 & 24.16 & 17.12 & 27.76 \\
\hline & 20 & 10.01 & 26.08 & 18.01 & 24.23 \\
\hline & 30 & 8.47 & 20.96 & 9.76 & 20.72 \\
\hline \multirow{4}{*}{0.24} & 0 & 8.08 & 20.99 & 12.41 & 24.02 \\
\hline & 10 & 8.85 & 23.48 & 10.78 & 24.39 \\
\hline & 20 & 8.06 & 25.82 & 11.51 & 25.53 \\
\hline & 30 & 8.71 & 18.27 & 12.81 & 22.92 \\
\hline
\end{tabular}

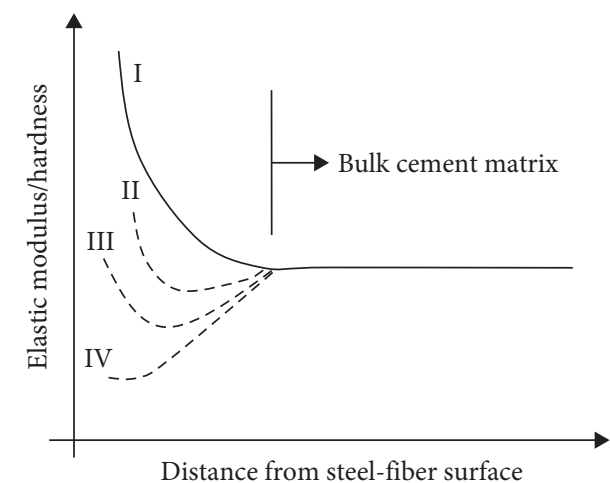

(a)

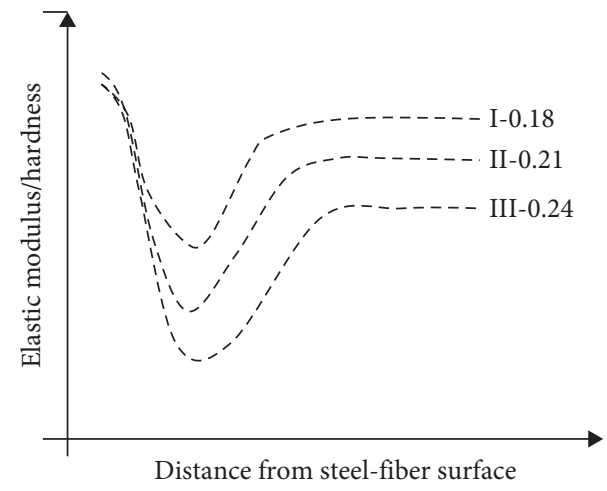

(b)

FIgURe 10: Continued. 


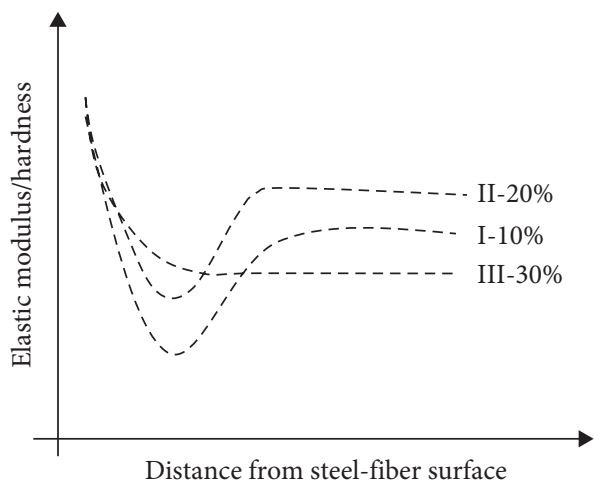

(c)

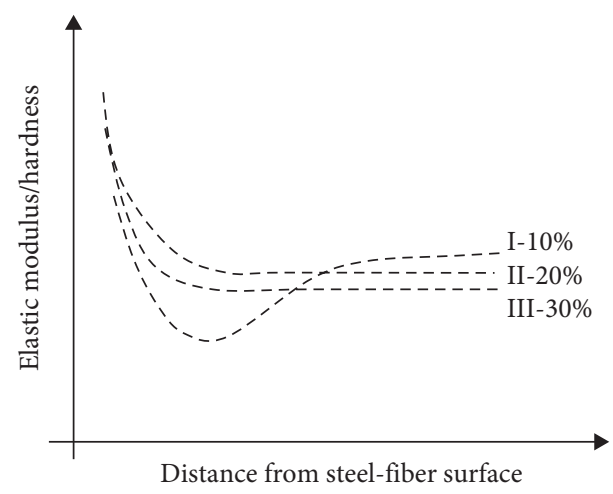

(d)

Figure 10: Profile characteristics of elastic modulus and indentation hardness in the ITZ. (a) Profile characteristics from the literature [20]. (b) Profile characteristics with different water-binder ratios and a silica fume content of $0 \%$. (c) Profile characteristics with water-binder ratio of 0.24 (d) Profile characteristics with water-binder ratio of 0.18 .

indentation hardness profiles with different water-binder ratios and silica fume contents were examined in the current study, and the curves depicted in Figure 10(a) do not account for the changes of the cement matrix properties as the ITZ properties change. In previous studies, it was not concluded that the macroscopic mechanical properties of concrete depend on the ITZ or the cement matrix. Therefore, in addition to the effect of ITZ on the mechanical properties of concrete, the concrete matrix must also be considered. It is necessary to summarize the profile characteristics of the elastic modulus and indentation hardness of the samples with different water-binder ratios and silica fume contents.

In this experiment, the profile characteristics of the elastic modulus and indentation hardness under different waterbinder ratios are shown in Figure 10(b). As water-binder ratio decreased (type III $\longrightarrow \mathrm{II} \longrightarrow \mathrm{I}$ ), the elastic moduli and indentation hardnesses increased in the ITZ and cement matrix. Furthermore, the ITZ did not disappear, which is different from the four types depicted in Figure 10(a).

For a higher water-binder ratio of 0.24 , the profile characteristics of the elastic modulus and indentation hardness for different silica fume contents are shown in Figure $10(\mathrm{c})$. With the increase of silica fume content (type $\mathrm{III} \longrightarrow \mathrm{II} \longrightarrow \mathrm{I}$ ), the elastic moduli and indentation hardnesses of the ITZ increased gradually, and the ITZ disappeared when the silica fume content was $30 \%$. However, the elastic modulus and indentation hardness of the cement matrix first increased and subsequently decreased.

For a higher water-binder ratio of 0.18 , the profile characteristics of the elastic moduli and indentation hardnesses of the ITZ with different silica fume contents are shown in Figure 10(d). With the increase of silica fume content (type $\mathrm{I} \longrightarrow \mathrm{II} \longrightarrow \mathrm{III}$ ), the elastic modulus and indentation hardness of the ITZ first increased and subsequently decreased, and the ITZ disappeared when the silica fume content was 20 or $30 \%$. However, the elastic modulus and indentation hardnesses of the cement matrix decreased gradually and were not constant.

\section{Conclusions}

(1) With the reduction of water-binder ratio in the range of $0.18-0.24$, the elastic modulus and indentation hardness of the ITZ and cement matrix increased, and the increase of the ITZ properties was greater than that of the cement matrix, yet the ITZ did not disappear.

(2) With the decrease of water-binder ratio, the total input energies $W_{\mathrm{t}}$ of the ITZ and the cement matrix increased, and the elastic deformation and energy dissipation capacities increased. With the decrease of the water-binder ratio, the ratio $\eta$ of the elastic deformation energy to the total input energy increased, which indicates the greater increase of the elastic deformation capacity than that of energy dissipation capacity. Under the same water-binder ratio, the elastic deformation and energy dissipation capacities of the cement matrix were higher than those of the ITZ, and the ratio of dissipation energy to the total input energy in the ITZ was higher than that in the cement matrix.

(3) With the increase of silica fume content in range of $0-30 \%$, the weak ITZ gradually strengthened or disappeared. In terms of obtaining the stronger ITZ, adding silica fume was more effective than reducing the water-binder ratio.

(4) When the water-binder ratio was high at 0.24 , a large silica fume content $(30 \%)$ resulted in obvious increase to the micromechanical properties of the ITZ 
and matrix, and the effect on the properties of ITZ was greater than that of the cement matrix. When the water-binder ratio was low at 0.18 , a large silica fume content (30\%) enhanced the micromechanical properties of the ITZ while degrading those of the cement matrix. Therefore, the silica fume content should not be too large for samples with a low waterbinder ratio (0.18).

\section{Data Availability}

The data used to support the findings of this study are included within the article.

\section{Conflicts of Interest}

The authors declare that they have no conflicts of interest.

\section{Acknowledgments}

The authors are grateful for support from the National Natural Science Foundation of China (nos. 11362013 and 11762015).

\section{References}

[1] W. Sun and C. W. Miao, Modern Concrete Theory and Technology, Science Press, Beijing, China, 2012.

[2] Z. Jia, Y. Han, Y. Zhang, C. Qiu, C. Hu, and Z. Li, "Quantitative characterization and elastic properties of interfacial transition zone around coarse aggregate in concrete," Journal of Wuhan University of Technology, vol. 32, no. 4, pp. 838-844, 2017.

[3] A. U. Nilsen and P. J. M. Monteiro, "Concrete: a three phase material," Cement and Concrete Research, vol. 23, no. 1, pp. 147-151, 1993.

[4] T. Akçaoğlu, M. Tokyay, and T. Çelik, "Effect of coarse aggregate size and matrix quality on ITZ and failure behavior of concrete under uniaxial compression," Cement Concrete Composites, vol. 26, no. 6, pp. 633-638, 2004.

[5] T. Akçaoğlu, M. Tokyay, and T. Çelik, "Assessing the ITZ microcracking via scanning electron microscope and its effect on the failure behavior of concrete," Cement Concrete Research, vol. 35, no. 2, pp. 358-363, 2005.

[6] S. Diamond and J. D. Huang, "The ITZ in concrete-a different view based on image analysis and SEM observations," Cement Concrete Composites, vol. 23, no. 2-3, pp. 179-188, 2001.

[7] A. Bentur and M. G. Alexander, "A review of the work of the RILEM TC 159-ETC: engineering of the interfacial transition zone in cementitious composites," Materials and Structures, vol. 33, no. 226, pp. 82-87, 2000.

[8] P. Mondal, S. P. Shah, and L. Marks, "A reliable technique to determine the local mechanical properties at the nanoscale for cementitious materials," Cement and Concrete Research, vol. 37, no. 10, pp. 1440-1444, 2007.

[9] L. Sorelli, G. Constantinides, F.-J. Ulm, and F. Toutlemonde, "The nano-mechanical signature of ultra high performance concrete by statistical nanoindentation techniques," Cement and Concrete Research, vol. 38, no. 12, pp. 1447-1456, 2008.

[10] X. H. Wang, S. Jacobsen, J. Y. He, Z. L. Zhang, S. F. Lee, and H. L. Lein, "Application of nanoindentation testing to study of the interfacial transition zone in steel fiber reinforced mortar,"
Cement and Concrete Research, vol. 39, no. 8, pp. 701-715, 2009.

[11] L. H. Xu, H. Y. Yu, Y. Chi, F. Deng, and J. Hu, "Nano-indentation character of interfacial transition zone between steel fiber and cement paste," Journal of the Chinese Ceramic Society, vol. 44, no. 8, pp. 1134-1146, 2016.

[12] J.-Y. Kim, J.-J. Lee, Y.-H. Lee, J.-i. Jang, and D. Kwon, "Surface roughness effect in instrumented indentation: a simple contact depth model and its verification," Journal of Materials Research, vol. 21, no. 12, pp. 2975-2978, 2006.

[13] M. Miller, C. Bobko, M. Vandamme, and F.-J. Ulm, "Surface roughness criteria for cement paste nanoindentation," $\mathrm{Ce}$ ment and Concrete Research, vol. 38, no. 4, pp. 467-476, 2008.

[14] GB/T22458-2008, General Rules of Instrumented Nanoindentation Test.

[15] W. C. Oliver and G. M. Pharr, "An improved technique for determining hardness and elastic modulus using load and displacement sensing indentation experiments," Journal of Materials Research, vol. 7, no. 6, pp. 1564-1583, 1992.

[16] J. Nemecek, "Creep effects in nanoindentation of hydrated phases of cement pastes," Materials Characterization, vol. 60, no. 9, pp. 1028-1034, 2009.

[17] P. Mondal, S. R. Shah, and L. D. Marks, "Nanoscale characterization of cementitious materials," ACI Materials Journal, vol. 105, no. 2, pp. 174-179, 2008.

[18] T. H. Zhang, Micro/nano Mechanics Testing Technology, Science Press, Beijing, China, 2013.

[19] J. William, Engineering Tribology, Cambridge University Press, Cambridge, UK, 2005.

[20] W. Sun, J. A. Mandel, and S. Said, "Study of the interface strength in steel fiber-reinforced cement-based composites," Journal of the American Concrete Institute, vol. 83, no. 4, pp. 597-605, 1986.

[21] W. Zhu and P. J. M. Bartos, "Application of depth-sensing microindentation testing to study of interfacial transition zone in reinforced concrete," Cement and Concrete Research, vol. 30, no. 8, pp. 1299-1304, 2000.

[22] S. Igarashi, A. Bentur, and S. Mindess, "The effect of processing on the bond and interfaces in steel fiber reinforced cement composites," Cement and Concrete Composites, vol. 18, no. 5, pp. 313-322, 1996.

[23] J. Nmeček, P. Kabele, and Z. Bittnar, "Nanoindentation based assessment of micromechanical properties of fiber reinforced cementitious composite," in Proceedings of the 6th RILEM Symposium on Fiber-Reinforced Concretes, pp. 401-410, RILEM Publications SARL, Varenna, Italy, 2004.

[24] S. Igarashi, A. Bentur, and S. Mindess, "Microhardness testing of cementitious materials," Advanced Cement Based Materials, vol. 4, no. 2, pp. 48-57, 1996. 